\title{
AN ASSESSMENT OF CURRICULUM-SPECIFIC LEARNING DIFFICULTIES IN NATURAL SCIENCES WITHIN THE SOUTH AFRICAN CONTEXT
}

\author{
Mafor Penn' ${ }^{1}$ \& Ramnarain Umesh ${ }^{2}$ \\ ${ }^{1}$ Department of Childhood Education, University of Johannesburg (South Africa) \\ ${ }^{2}$ Department of Science and Technology Education, University of Johannesburg (South Africa)
}

\begin{abstract}
Some of the identified difficulties across science subjects are universal and have seen education researchers advocate for several reforms in science curricula globally. Internationally and in South Africa, several science concepts within chemistry and physics have been associated with abstraction, representational complexities and the use of scientific terminology. This study reports the findings of curriculum specific difficulties identified by 3rd year science education students at a South African university. The main aim of the study was to assess perceived difficulties of concepts within the natural sciences school curriculum. 120 third year students in a teacher training program from two different cohorts participated in the survey which was analysed descriptively. At the end of the survey period semi-structured interviews were conducted with five percent $(n=6)$ of the participants, to validate survey findings and obtained the rationale for perceived difficulties. Findings from the study indicated that, for subjects within the natural sciences, chemistry and physics topics were perceived to be more difficult than biology and earth science topics. Descriptive analysis of the data indicated that the topics, "chemical reactions, balancing equations, forces, visible light (optics), the law of energy conservation, animals with skeleton and biodiversity", were considered the most difficult topics within the natural sciences curriculum. Finding from follow-up semi-structured interviews indicated that, factors like abstraction, the language of science and representational complexities were the key reasons for perceived difficulties experienced by students in learning these topics. We concluded that the identification of context-specific difficulties associated with science learning is crucial in developing solutions that address low performances in science and increase interest in science. The implications for these findings and some recommendations for practice and research are also proposed herein.
\end{abstract}

Keywords: Difficulties, representation, natural sciences, abstraction, scientific language.

\section{Introduction and background}

Over several decades globally science has been continuously perceived to be among some of the the most difficult subjects to learn for similar reasons across the board (Achor \& Agbidye, 2014; Sokrat, Tamani, Moutaabbid \& Radid, 2014). Reasons like abstraction, misconceptions associated to the use of language, micro-representational complexities and science teachers' pedagogical approaches for teaching the subject are among some factors implicated for poor performance in science (Harle and Towns, 2011; Kempa, 1991; Otor \& Achor, 2013; Reddy, Visser, Winnaar, Arends, Juan \& Prinsloo, 2016). These perceived difficulties constitute some of the reasons science students show less interest in science subjects, low motivation towards science and negative attitudes towards science subjects and science related careers (Reddy, Visser, Winnaar, Arends, Juan \& Prinsloo, 2016).

In (1991), Kempa, proposed a rather narrow definition of learning difficulties to mean "situations where a student fails to grasp a concept or ideas as the result of several factors" (kempa, 1991, p. 119). In his review, he indicated that these factors might include the nature of ideas and knowledge possessed by the student, complexity of learning task, communication problems from the use of language, and mismatched instructional approaches.

In science education in particular, strategies of addressing the learning difficulties historically have included, inquiry -based teaching and learning approaches ((Department of Basic Education [DBE], 2011), science by discovery, collaborative and peer learning, multi-media enhanced learning (Lee \& Park, 2016; Penn \& Ramnarain, 2019a). This study therefore exploited a two-fold research gap in firstly acknowledging that, despite the numerous solutions available for the demystification of science subjects, 
not many studies in the South African context have reported topics within the natural sciences grade 7-9 curriculum which are perceived to be difficult form learners' and teachers' perspectives. The second gap touches on the need for concept-specific teaching and learning approaches targeted to address concept-specific learning difficulties. The study seeks to investigate natural sciences topics and concepts that pre-service teachers (here in also referred to as students) consider difficult, as a prerequisite to designing a broader intervention on topic specific learning pedagogical approaches that can address these difficulties. Ultimately, it is worth noting that when teachers perceive a topic as difficult, they may also find it hard to teach this topic to their learners. Hence, this study aimed at assessing pre-service teachers' natural sciences learning difficulties by answering the following research questions;

- To what extent do pre-service natural sciences teachers perceive concepts in the South African natural sciences school curriculum as difficult?

- What are the perceived reasons for learning difficulties in the identified concepts?

\section{Theoretical underpinnings}

The study is underpinned by cognitive constructivism which focuses on how science concepts are accommodated and assimilated within the mind of a learner (Piaget, 1970). In science concept formation, we recognise that for learning difficulties to be dispelled, there has to be a change of what is held as a preconception about a concepts and a change in what might be making a particular topic to be perceived by the mind as difficult (Sweller, 2015). Obvious therefore to science learning are concepts perceived as difficult due to underlying issues of abstraction, symbolic representation and complexities of scientific language. However, cognitive theorists hold that the learning process in science entails that student are able to maintain long-term schemas of the concepts they learn (Mayer, 2011).

\subsection{Difficulties associate with science learning}

Some of the problems associated with science education globally at primary and secondary school levels are related to poor performance, lower interest, poor enrolment in science subjects, perceived difficulty, abstraction, misconceptions and negative attitudes towards science subjects (Penn \& Ramnarain, 2019a; Reddy, Gastrow, Juan \& Roberts, 2013). Despite several global reforms in science curricula the world over, these issues still persist. In the case of pre-service teachers, some of them still hold learning difficulties in science that spanned their secondary school years. In several studies it has been identified that, the pedagogical approaches used for teaching certain concepts make them incomprehensible and relatively complex as they exist in three levels namely, micro, macro and representational or symbolic (Nadelson, Heddy, Jones, Taasoobshirazi, \& Johnson, 2018; Sokrat et al, 2014).

In chemistry for example, when looking at the reactions of group 1 elements, students, may be asked to interact with common salt which they can touch and feel at the macroscopic level, then at the micro-level where they are informed that a molecule of salt consist of elements sodium and chlorine; Lastly the representational or symbolic level where the same substance can be represented as $\mathrm{NaCl}$. The difficulty in learning concepts of this nature are associated to the fact that students' working memory becomes overloaded when the information is not adequately scaffolded across levels from the tangible to the representational (Penn \& Ramnarian, 2019b; Sweller, 2015). Furthermore, some science teachers tend to use all three levels of representation interchangeable in one lesson causing student to be confused and hold misconceptions (Sokrat et al, 2014).

\subsection{Pedagogical approaches for addressing difficulties in science learning}

Many pedagogical approaches like inquiry-based learning, the use of diverse representational tools like simulations, analogies, 3D illustrations, motion pictures and virtual laboratories are among the strategies proposed for addressing conceptual difficulties in science learning (Nadelson et al, 2018). However, the use of these pedagogical strategies must be consistent and deliberate to address topic and concept-specific learning difficulties in cases where traditional teaching approaches are unable to do so.

\section{Methodology and design}

The study followed a sequential mixed methods approach (Creswell \& Creswell, 2017), whereby quantitative data was initially collected using a modified perceived difficult questionnaire followed by qualitative data through the use of semi-structured interviews. The different aspects of the methodological approach are covered in the sections below. 


\subsection{The sample}

The sample for this study was purposively selected to included one hundred and twenty $(\mathrm{n}=120)$ natural sciences pre-services teachers at the faculty of education at a South African University. The rationale for focusing on these students and the natural sciences was to ensure that difficulties across school science subjects including biology, chemistry, physics and earth science could be identified.

\subsection{Data collection and analysis}

Data collection was conducted by means of the perceived difficulty in natural sciences learning questionnaire (PDNSL), adapted from the Rating Scale on Student Perceived Difficult Concepts in Basic Science (RSSPDCBS) (Achor \& Agbidye, 2014). The PDNSL questionnaire was reconstructed to cover 35 concepts/topics within the South African natural sciences grade 7-9 curriculum. The adapted instrument was first piloted by the researchers with students at another higher institution of learning and the internal consistency measured as cronbach's alpha. An $\alpha=0.85$ was reached for all of the 35 items on the instrument. The responses on items ranged from very difficult $(\mathrm{VD}=4)$, difficult $(\mathrm{D}=3)$, slightly difficult $(\mathrm{SD}=2)$ to not difficult $(\mathrm{ND}=1)$. The descriptive means for survey items represented perceived difficulty when they ranged from to 3.00-4.00. Follow-up semi-structured interviews were conducted with $5 \%(\mathrm{n}=6)$ of the participants post analysis of the PDNSL questionnaire, with the aim of establishing students' rationale for perceived difficulties.

Collected survey data was then captured and analysed using descriptive statistics on SPSS 25 to show a holistic pattern of concepts pre-service teachers considered difficult within natural sciences grade 7-9 curriculum. Transcribed textual data from semi-structured interviews were also analysed with the aid of Atlas Ti. version 8 following the principles of thematic content analysis to generate themes.

\section{Results}

Table 1 below shows the descriptive means of perceived difficult natural sciences concepts including only concepts where the mean was above 3.00 .

Table 1. Perceived difficult concepts in grade 7-9 natural sciences curriculum.

\begin{tabular}{||l|l|l||}
\hline Concept & Strand in the N/S CAPS & Mean \\
\hline Chemical reactions & Matter and material & 3.81 \\
\hline Balancing chemical equations & Matter and material & 3.58 \\
\hline Forces & Energy and change & 3.45 \\
\hline Visible light (optics), & Energy and change & 3.38 \\
\hline The law of energy conservation, & Energy and change & 3.35 \\
\hline Animals with skeleton & Life and Living & 3.15 \\
\hline Biodiversity & Life and Living & 3.11 \\
\hline Beyond the solar system & Earth and Beyond & 3.09 \\
\hline
\end{tabular}

** N/S CAPS $=$ Natural Sciences Curriculum and Assessment Policy Statement (CAPS).

The table above presents the related areas in the natural sciences school curriculum where pre-service teachers consider concepts as difficult, in an attempt to answer the first research question. The strand matter and material is a chemistry strand of the curriculum while the strand energy and changes represents the physics content within the CAPS natural sciences curriculum. The topics in these two strands (chemistry and physics) were perceived to be more difficult as they registered difficulty means between $\mathrm{M}=3.35-3.81$ than topics in the biology strand (Life and living) and the earth science strand (Earth and beyond) where difficulty means ranged between $M=3.09-3.15$. These results provided a pattern for the researchers to design questions that further probe participants' rationales for perceived difficulties.

In answering the second research, findings from thematic content analysis of semi-structured interviews revealed that, factors like inherent abstraction, the language of science and representational issues were key reasons for perceived difficulties experienced by students in learning these topics. The participants also indicated that several complexities to learning concepts were related to the pedagogical approaches used to teach the concepts. Three themes generated include: 
- Concepts are inherently abstract to learn due to lack of visualisation.

- Scientific language is difficult to grasp in some concepts.

- Symbolic representation is complex and needs to be scaffolded.

The participants also highlighted that pedagogical approaches were related to these identified themes in several ways. It was then clear from the intepretivist views of the researchers that, the nature of every scientific concept must be considered in several dimensions when planning the pedagogical strategies for teaching the concept.

\section{Discussions}

The findings from this study present a baseline understanding of difficult concepts within the South African natural sciences CAPS curriculum. These findings suggest that learning difficulties in science are related to the nature of particular concepts and how they are taught. (Achor \& Agbidye, 2014). The findings are concurrent with findings from other difficulty studies which have implicated factors like abstraction, representation, visualisation and pedagogy for some of the barriers to science concept formation (Achor \& Agbidye, 2014; Sokrat, Tamani, Moutaabbid \& Radid, 2014). Unique to this study is that, these findings provide a pre-requisite dimension for the development of concept-specific learning interventions that address difficulties in learning specific natural sciences concepts. The perceptions of participant also indicate that a "one size fit all" solutions cannot be adequate in addressing the problems and difficulties associated to science learning.

\section{Conclusion and recommendations}

Based on the findings of this study we concluded that the identification of concept-specific difficulties associated with different science subjects is crucial in developing solutions that address low performances in science and increase interest in science. The implications for teachers and pedagogues across all levels are that, the manner in which concepts are taught to students has a direct relationship to the way in which they learn and retain understandings of these concepts. Several studies have revealed that multiple representations, inquiry-based learning and activity -based learning could provide some of the much needed improvements in science achievement. However, based on the findings of this current study we conclude that these proposed pedagogical approaches must be intentionally planned to address the inherent factors that make concepts difficult to grasp. Some recommendations for practice and research are targeted at investigating how specific learning interventions could be used to address concept-specific difficulties in natural sciences learning; An investigation of the relationship between perceived difficulties in science learning and achievement in science for specific concepts and an analysis of the strategies that in-service teachers use to address concept difficulties as they teach natural sciences within the school curriculum.

\section{References}

Achor, E. E., Agbidye, A. (2014). Students' Perceived Difficult Concepts and its Influence on their Performance in Basic Science in Makurdi Metropolis: Implications for Basic Science Teacher Production. NASHERJ , (12)1, $24-31$.

Creswell, J. W., \& Creswell, J. D. (2017). Research design: Qualitative, quantitative, and mixed methods (5th ed.). Thousand Oaks, CA: Sage

Department of Basic Education. (2011). Curriculum and assessment policy statement: Grades 7-9 Natural Sciences. Pretoria: Government Printer.

Harle M. and Towns M., (2011), A review of spatial ability literature, its connection to chemistry and implications for instruction. Journal of Chemistry Education, 88(3), 351-360, DOI: $10.1021 /$ ed900003n.

Kempa, R.F. (1991). Students' learning difficulties in science. Causes and possible remedies. Enseñanza de las ciencias, 9 (2), 119-128.

Lee, J., \& Park, H. (2016). A Study on cases for application of flipped learning in K-12 education. Journal of Digital Convergence, 14(8), 19-36.

Mayer, R. E. (2011). Instruction based on visualizations. In R.E. Mayer \& P.A. Alexander (Eds.), Handbook of Research on Learning and Instruction. New York: Routledge.

Nadelson, L.S.; Heddy, B.C; Jones, S.; Taasoobshirazi, G. \& Johnson, M. (2018). Conceptual Change in Science Teaching and Learning: Introducing the Dynamic Model of Conceptual Change. International Journal of Educational Psychology, 7(2), 151-195.doi:10.17583/ijep.2018.3349 
Otor, E. E., \& Achor, E. E. (2013). Effect of concept mapping strategy on students' attitude in difficult chemistry concepts. European Journal of Educational Sciences, 1(3), 116-124.

Penn, M. \& Ramnarain, U. (2019a). South African university students' attitudes towards chemistry learning in a virtually simulated learning environment. Chemistry education research and practice, 4(20), 699-709. http// doi: 10.1039/c9rp00014c.

Penn, M., \& Ramnarain, U. (2019b). Assessing the role of implicit scaffolding in facilitating virtual physical sciences learning. In proceedings of the $10^{\text {th }}$ Annual UNISA ISTE Conference on Mathematics, Science and Technology Education: 21-25 October 2019 Maponi Camp, Kruger National Park, Mpumalanga, South Africa. (pp. 250-256) Page numbers 250-256 ISBN 978-1-77615-062-5.

Piaget, J. (1970). Piaget's theory. In P. H. Mussen (Ed.), Carmichael's manual of child psychology (3rd ed., Vol. 1, pp. 703-732). New York: Wiley

Reddy V., Visser M., Winnaar L., Arends F., Juan A. and Prinsloo C. H., (2016), TIMSS 2015: Highlights of Mathematics and Science Achievement of Grade 9 South African Learners, Human Sciences Research Council.

Reddy, V., Gastrow, M., Juan, A., \& Roberts, B. (2013). Public attitudes to science in South Africa. South African Journal of Science, 109(1/2), 1-8. . http://dx.doi.org/10.1590/sajs.2013/1200

Sokrat, H., Tamani, S., Moutaabbid, M. \& Radid, M. (2014). Difficulties of students from the faculty of science with regard to understanding the concepts of chemical thermodynamics. Procedia - Social and Behavioral Sciences, 116, 368 - 372. doi: 10.1016/j.sbspro.2014.01.223

Sweller, J. (2005). Implications of cognitive load theory for multimedia learning. In R. E. Mayer (Ed.). The Cambridge handbook of multimedia learning (pp. 19-29). New York, NY: Cambridge University Press 